\title{
Research in Academic Sector: Prospect and Challenges
}

Research in general is systematic investigation into and study of materials and sources in order to establish facts and reach new conclusions. The main purpose of research is to discover, explore, document and interpret the scenario which calls for proper policy or program intervention to address the diagnosed problem/ situation. Dissemination of findings through publication of scientific paper holds an important aspect in overall process of research. The publication culture in Nepal dates back to 1963 with journal by Nepal Medical Association. Nearly after five decades we have about 43 listed journals in NepJol, Health Prospect being one of its kinds.

With the evolvement of education system in Nepal, academic level research has been introduced in many undergraduate courses of health sciences like public health, medicine, social science, rural development and the list continues. National Health Research Policy-2003, also promotes research on biomedical, clinical and behavioral sciences, public health, health economics, health policy, traditional medicine, and other areas as one of the important strategy for promotion of health researches in Nepal. This policy guides for incorporation of health research in core curriculum in the bachelor level health science. It furthermore calls for undergraduate grants, post graduates grants, young research grants to develop health research cultures in universities, medical institutes and other related health institutions. Research followed by publication of scientific papers is one of the major criteria for scholarship in abroad or international universities. These overall scenarios have underpinned and sensitized young scholars towards research in present days.

Introduction of research in undergraduate courses is useful in sensitizing basic process of research and its methodology and stimulates further research in future. It is helpful in making students aware of the health problems of the community and country thus enabling them to acquire academic qualification as well as judicious insight too.

During initial phase, few journals with few issues majorly published biomedical articles overshadowing public health issues. At current state, JNHRC and Health Renaissance give priority to public health research, while other major journals are biomedical. Amidst of high submission, research of young graduates is often neglected. It is notable in recent years, many researches by young Nepalese students have been accepted in popular international journals. Researches done on health issues in Nepal co-authored by foreign author are also being published in renowned journals. Arguably, this is matter of both pride and challenge. Health issues of Nepal are being articulated in international arena whereas local or national sector where the issues could have made greater impact is severely deprived.

Though research has been imbedded within the curriculum but irony stands that they pass very minimum standard. Universities and health institutions providing research as academic course either lacks necessary faculties or environment conducive to it. Students are poorly oriented for research activitiesa and it has created a bigger problem; after all "little knowledge is dangerous". Lack of proper time allocation within the course, financial constraints, poor knowledge on scientific writings and inadequate guidance have created a negative and burdensome attitude towards research among these young cadres. It is further supplemented by lack of follow of sampling procedure, lack of validation of sampling tools, high plagiarism, fabrication of data and lack of ethical clearance. Students intentionally or unintentionally tend to do these rampant mistakes. These problems are recognized widely but poorly addressed.

There are thousands of students from different faculties who have to submit a research mandatorily for passing their undergraduate and post graduate degrees. But, the quality of researches being conducted poses a serious question. There is neither the mechanism nor any environment to check and maintain the reliability and validity of research being conducted. Researches done by these students usually end up in the closed racks of concerned departments or to the researcher himself/herself. A huge amount of grey literature gets piled upeach year. These issues are often ignored because neither students nor faculties bother to overlook 
the research once it is submitted and marks are allocated. These practices have undermined the spirit of conducting research to a larger extent for upcoming generations. If properly disseminated and published, these small literatures could be milestone to enhance further knowledge and address the problem at local level.

Ethical clearance is one of the prerequisites to strengthen the research being conducted. Every research whether basic or applied has to be passed through the ethical review board and it's mandatory. NHRC and Institutional Review Board (IRB), IOM are major responsible agencies for checking and maintaining ethical standard. But, this step is often skipped in the research by young researchers. Neglecting few exceptions, majority of researches do not pass through this procedure though scientific papers from the research are being published.

Contemplating the current scenario, still many bottlenecks exist in the field of research by undergraduates. It is the time to develop research culture among students and health professionals to look research as more than just a subject, to appreciate its importance and value beyond the marks being rewarded. No matter how small or primitive the research is, a methodologically strong research always provides and generates new knowledge. Appropriate research training for students and mainstreaming research within the curriculum is the need of time and a vital action to lead a change in research related practices over time. 